\title{
Limiting Permissible Limitations: How to Preserve the Substance of Religious Freedom
}

\author{
Heiner Bielefeldt \\ Professor/Chair in Human Rights and Human Rights Politics at the \\ University of Erlangen-Nuremberg and former United Nations Special \\ Rapporteur on Freedom of Religion or Belief (2010-2016) \\ heiner.bielefeldt@fau.de
}

\begin{abstract}
The question of how to draw legitimate limits to the content and exercise of human rights has caused many controversies, not only in academic debates, but also in human rights practice. Governments often invoke limitation clauses linked to human rights provisions as a broad allowance to impose restrictions. However, the main function of those clauses is actually to limit the scope of permissible limitations. This chapter takes freedom of religion or belief as a test case to illustrate the role of limitation clauses. Moreover, from an adequate understanding of limitation clauses, the popular "balancing" semantics deserves serious criticism, since it obfuscates the task to preserve the substance of human rights guarantees even in situations of normative conflict.
\end{abstract}

\section{Keywords}

freedom of religion or belief - limitation clauses - proportionality - forum externum and forum internum

Limitation clauses as part of human rights provisions seem to be a complicated technical issue. They require special knowledge, including an understanding of proportionality testing and other jurisprudential principles. Thus, those human rights activists who are more interested in the "substance" of 
rights may prefer to leave such "procedural" aspects to specialized lawyers. Moreover, in addition to being complicated, limitation clauses may also cause feelings of disappointment. Participants of human rights trainings sometimes show frustration when, after days of hearing heart-warming stories about the empowerment function of human rights, they eventually realize that there is another side of the equation. What remains of the elevated status of "inalienable" rights, when interests of public safety or public order and the like can limit those rights? Does this not mean that human rights end up as mere variables of unpredictable negotiations between the advocates of freedom and the promoters of law and order? Even worse, anti-liberals like Carl Schmitt have tried to unmask fundamental rights and the rule of law as a mere luxury for times of peace and tranquillity. In any serious political crisis, Carl Schmitt contends, security issues will ultimately have the upper hand. ${ }^{1}$ Does the existence of limitation clauses within human rights instruments not indicate that there is a grain of truth in such gloating comments? Are human rights, at the end of the day, but a dividend of successful security management?

At first glance, limitation clauses may look like a somewhat unpleasant theme for human rights enthusiasts, perhaps even a bit awkward. However, at a closer look this impression changes. It is true that limitation clauses accommodate a degree of pragmatic elasticity in the implementation of human rights law. Without such pragmatic concessions, human rights would not work in practice. Human rights are not a utopian dream; they are for the real world. Yet the main function of limitation clauses is not to allow certain limitations, but to set up criteria by which to limit the scope of permissible limitations. To highlight this purpose, German jurisprudence has coined the artificial cluster word "Schranken-Schranken", which in literal translation means "limits to limits". Although admittedly sounding a bit strange, this word nicely captures the specific function of limitation clauses. Their goal is to preserve the substance of human rights provision in complicated situations, when a human rights-based interest collides, or seems to collide, with important public goods or with the rights and freedoms of others. By insisting on the fulfilment of a number of criteria, limitation clauses prevent the easy invocation of the (alleged) need to impose limitations - or this is the guiding idea. Rather than becoming entry points for selling out the substance of human rights, limitation clauses play a critical role in defending the status and the scope of those rights. Understanding this positive function is important not only for legal specialists, but ultimately for everyone interested in human rights. Accordingly, this

1 See Carl Schmitt, Political Theology: Four Chapters on the Concept of Sovereignty, transl. of the 2nd edition of 1932 by George D. Schwab (Cambridge: MIT Press, 1985). 
should be a theme also in human rights education and training programmes for civil society organizations broadly. Few issues are more relevant for human practice than the adequate interpretation and handling of limitation clauses.

In this article, I deal with the issue of limitations from the perspective of legal philosophy. ${ }^{2}$ Instead of analysing individual cases, the focus is on the general principles that should guide the practice of limitation clauses, always bearing in mind their specific role as "Schranken-Schranken". To illustrate the task at hand, I have taken the example of freedom of religion or belief (FoRB), as it is enshrined in article 18 of the International Covenant on Civil and Political Rights (ICCPR). ${ }^{3}$ When discussing the role and the content of the limitation clause spelt out in article 18, paragraph 3, I repeatedly refer to General Comment no. 22 issued in 1993 by the UN Human Rights Committee, the independent expert body tasked with the monitoring of the ICCPR. ${ }^{4} \mathrm{My}$ first systematic point is that the relationship between the exercise of the right to FoRB, on the one hand, and any proposed limitation to FoRB, on the other, is a relationship between rule and exception. Whereas no one has to "justify" their use of FoRB, which has the status of an inalienable human right after all, any proposed limitation by contrast, needs a plausible justification, in accordance with the criteria defined for that purpose (see section 2). Subsequently, I criticize the frequently used metaphor of "balancing", since it harbours the danger of trivializing the critical function of limitation clauses in general. The balancing semantics seems to suggest that the human right at issue and proposed limitations are competing considerations of symmetrical status, whose conflicts should be settled by some sort of compromise in the middle ground of both. Instead of resorting to such vague balancing, I argue, one should rather

2 My background is mainly Kantian philosophy, broadly speaking. I also draw on discourse ethics, in particular the way it has been elaborated by Jürgen Habermas. See also Heiner Bielefeldt, Philosophie der Menschenrechte (Darmstadt: Wissenschaftliche Buchgesellschaft, 1998).

3 Here is the wording of article 18 and its 4 paragraphs: '1. Everyone shall have the right to freedom of thought, conscience and religion. This right shall include freedom to have or to adopt a religion or belief of his choice, and freedom, either individually or in community with others and in public or private, to manifest his religion or belief in worship, observance, practice and teaching. 2. No one shall be subject to coercion which would impair his freedom to have or to adopt a religion or belief of his choice. 3. Freedom to manifest one's religion or beliefs may be subject only to such limitations as are prescribed by law and are necessary to protect public safety, order, health, or morals or the fundamental rights and freedoms of others. 4. The States Parties to the present Covenant undertake to have respect for the liberty of parents and, when applicable, legal guardians to ensure the religious and moral education of their children in conformity with their own convictions.'

4 See UN Human Rights Committee, General Comment no. 22-Article 18 (Freedom of Thought, Conscience or Religion) (CCPR/C/21/Rev.1/Add.4). [General Comment no. 22] 
stick to strict justification requirements (see section 3). Additional complication may arise when two or more human rights collide. Many examples come to mind where FoRB stands, or seems to stand, in conflict with other human rights, such as the right to education, the right to health, freedom of expression or gender equality. The point I want to make in this regard is that an adequate handling of such complicated constellations requires a holistic understanding of the various human rights at issue, none of which can be sacrificed for the sake of another right (see section 4). I then move to exploring the differentiation between the forum internum and the forum externum of FoRB. While the inner nucleus of a person's faith formation remains immune from any legitimate limitations, the dimension of external manifestations of religious or belief-related convictions does carry a limitation clause. At the same time, the absolute protection of the forum internum has significance for the forum externum of FoRB, too, because at the end of the day these dimensions belong together (see section 5). In my concluding remarks I argue that the reflections made here with regard to FoRB are relevant for the interpretation of limitation clauses more broadly, including freedom of expression, freedom of peaceful assembly, freedom of associations and other human rights to freedom (see section 6).

Human rights enjoy an elevated rank within the legal order, since they institutionalize the due respect for everyone's human dignity. The preamble of the 1948 Universal Declaration of Human Rights (UDHR) begins with the 'recognition of the inherent dignity and of the equal and inalienable rights of all members of the human family'. This wording creates a systematic link between human dignity and human rights. Given their significance in protecting everyone's inherent dignity, human rights furthermore claim the special authority of "inalienable" rights, in which no less than the humanness of the human being is at stake. Being 'endowed with reason and conscience', ${ }^{5}$ all human beings deserve respect for their potential of responsible agency, which is tantamount to respecting their human dignity. ${ }^{6}$ To say it with Immanuel Kant: 'every human

5 This formulation occurs in article 1 of the UDHR.

6 According to the UDHR, human dignity is a universalistic concept. It must be accorded to all human beings equally, including those who, for whatever reason, factually cannot fully use their potential of responsible agency, e.g. persons with mental disabilities or dementia. See Suzanne Cahill, Dementia and Human Rights (University of Bristol: Policy Press, 2018). 
being still has his inalienable rights, which he can never give up even if he wanted to ....7

Inalienable rights are not necessarily absolute rights. Given the experience of numerous conflicts in all societies, certain limitations to the use of human rights may actually prove unavoidable. However, to do justice to the special rank of human rights, limitations always require a compelling justification. Setting up the criteria for such justification is the raison d'être of limitation clauses. The formulation in article 18(3) of the ICCPR is as follows: 'Freedom to manifest one's religion or belief may be subject only to such limitations as are prescribed by law and are necessary to protect public safety, order, health, or morals or the fundamental rights and freedoms of others.' The verb "to manifest" indicates that this paragraph deals with the forum externum of FoRB, while the forum internum, i.e. the inner nucleus of a person's faith formation, remains immune from any legitimate interference, as emphasized in article 18(2) of the ICCPR. (I will come back to this issue below, in section 5.) The need for setting limits can merely arise, if certain manifestations of religiosity affect important public goods or other people's rights and freedomshence the focus on the forum externum of FoRB. However, the most important term within article 18(3) is the little word "only". The formulation "subject only to such limitations ..." defines the critical thrust of the entire sentence: While the enjoyment of FoRB is the rule, limitations must remain exceptions to that rule. In other words, the relationship between the exercise of FoRB and any limitations to FoRB is not a symmetrical one; it is a relationship of rule and exception. ${ }^{8}$

Keeping that rule-exception-structure intact is of utmost importance for preserving the substance of human rights guarantees in practice. In reality, however, that structure is often blurred, sometimes even turned upside down. Governments, in particular authoritarian governments, like to invoke

7 Immanuel Kant, 'On the Common Saying: This May be Correct in Theory, But it is of No Use in Practice', in Immanuel Kant, Practical Philosophy (Cambridge: Cambridge University Press, 1996), p. 302.

8 Some commentators seem to ignore the crucial function of the term "only". See e.g. Lorenzo Zucca, 'Freedom of Religion in a Secular World', in S. Rowan Cruft et al. (eds.), Philosophical Foundations of Human Rights (Oxford: Oxford University Press, 2015), p. 398: 'The strength of the interest protected by freedom of religion can be limited on the basis of interests of public safety, for the protection of public order, health or morals, and finally-last but not least - for the protection of the rights and freedoms of others.' Zucca here refers to article 9 of the European Convention of Human Rights. The limitation clause in that article is almost identical to the wording of article 18 of the ICCPR and follows the same logic. It is remarkable and indeed revealing that Zucca ignores the crucial word "only" when paraphrasing the limitation clause. 
limitation clauses to human rights in loose and unspecified ways, so as to claim broad leeway for themselves. Thus, they factually define the scope of people's FoRB, as they see fit. By contrast, the right holders themselves, in particular religious minorities, converts or dissenters, may end up in a situation where they have actually to justify the use of FoRB. In the face of such restrictive twists, the wording used in article 18(3) of the ICCPR proves even more significant. The formulation "subject only to such limitations ..." clarifies that limitations are prima facie impermissible unless receiving a plausible justification in line with the criteria listed in article 18(3) of the ICCPR.

What are these criteria? ${ }^{9}$ Firstly, limitations must be "legally prescribed". Given the high normative rank of human rights, any interference, when deemed necessary, cannot be left to the administration, the police or whoever just happens to exercise state authority. The requirement of a legal basis sets a formal threshold by involving the legislator. Secondly, in order to be justifiable, a limitation must pursue a legitimate goal, namely, the protection of 'public safety, order, health, or morals or the fundamental rights and freedoms of others'. This list of possible goals is exhaustive. Thirdly, the limitation at issue must actually prove "necessary" to pursue the said goal. In other words, it must respond to a pressing societal need. If various options are available to achieve the needed result, the state is obliged to go for the least far-reaching interference. The necessity criterion prescribes the mildest possible measure; this is part of the proportionality testing. ${ }^{10}$ In addition to all of this, everyone should have access to legal remedies in order to rectify unjustified infringements.

The UN Human Rights Committee, which monitors the implementation of the ICCPR, insists on a strict and narrow interpretation of these criteria. In its General Comment no. 22, which deals with the understanding of FoRB, the Committee emphasizes 'that paragraph 3 of article 18 is to be strictly interpreted: restrictions are not allowed on grounds not specified there ... Limitations may be applied only for those purposes for which they were prescribed and must be directly related and proportionate to the specific need on which they are predicated. Restrictions may not be imposed for discriminatory purposes or applied in a discriminatory manner.'11 This narrow interpretation of the limitation clause stands in stark contrast to the wide interpretation of the

For a more detailed analysis, see Heiner Bielefeldt, Nazila Ghanea, Michael Wiener, Freedom of Religion or Belief. An International Law Commentary (Oxford: Oxford University Press, 2016), pp. 551-570.

10 Beside sub-criterion of necessity, the proportionality also includes the sub-criteria of suitability (i.e. suitability of limitation actually to serve the purpose that it is supposed to pursue) and adequacy. 
protected right itself. According to the Human Rights Committee, FoRB is 'farreaching and profound; it encompasses freedom of thought on all matters, personal conviction and the commitment to religion or belief, whether manifested individually or in community with others.' ${ }^{12}$ The General Comment furthermore demands a broad conceptualization of the terms "religion" and "belief", far beyond certain traditional forms of religiosity. Furthermore, FoRB covers 'theistic, non-theistic and atheistic beliefs', ${ }^{13}$ thus also including people many of whom would call themselves "non-believers". With regard to practical manifestations of belief, the Human Rights Committee likewise insists on a wide interpretation, thereby covering 'a broad range of acts' following from a religion or belief. ${ }^{14}$ Hence, whereas the content and scope of the human right at issue span a very wide spectrum of religious or belief-related convictions as well as concomitant practical manifestations, the conceptualization of the criteria for limitations is narrow. This again accounts for the critical function of the limitation clause in limiting the space of permissible limitations. ${ }^{15}$

When it comes to presenting arguments pro or contra a proposed limitation, the onus of justification falls on the pro side, i.e. on those who argue for the limitation. This is an important point, upon which much depends. As said before, no one has to justify their exercise of FoRB or their support of the enjoyment of that right by others. People do not receive their human rights in exchange to acts of loyalty vis-à-vis the government. These rights are inextricably connected with the humanness of every human being and thus always deserve respect. This is the premise upon which the whole architecture of human rights rests. While the exercise of human rights does not require any justification, limitations and interferences, by contrast, always do. In other words, the relationship between the exercise of human rights and limitations to those rights is not symmetrical. The asymmetry of rule and exception implies that the burden of justification falls on one side only, name on those who deem limitations necessary. ${ }^{16}$ This asymmetrical relationship, however, can get blurred

12 Ibid., paragraph 1.

13 Ibid., paragraph 2.

14 Ibid., paragraph 4.

15 The General Comment also deals with "morals", which is one of the purposes on behalf of which FoRB manifestations can be limited. Obviously, the notion of "morals" can easily be filled with paternalistic and moralistic ideologies. Hence the clarification (in paragraph 8 ) 'that the concept of morals derives from many social, philosophical and religious traditions; consequently, limitations on the freedom to manifest a religion or belief for the purpose of protecting morals must be based on principles not deriving exclusively from a single tradition.'

16 See also T. Jeremy Gunn, 'Permissible Limitations on the Freedom of Religion or Belief', in John Witte, Jr. and M. Christian Green (eds.), Religion and Human Rights. An Introduction 
by the ubiquitous presence of the metaphor of "balancing", which therefore warrants critical scrutiny.

\section{Pitfalls of "Balancing"}

The balancing semantics is widespread in human rights literature, including in court decisions and reports by monitoring agencies. Whenever complicated normative conflicts arise, commentators seem to find it intuitively plausible to resort to the need of striking some sort of balance. Moreover, many people actually like the language of balancing. Indeed, it is an attractive word, since it suggests sophistication and a careful and nuanced position. A "balanced" approach is characterized by the aspiration to accommodate diverse perspectives and to do justice to different interests. In that sense, "balancing" represents complexity and multiperspectivity. This may account for the extraordinary popularity of the term, not least in the context of human rights.

However, the metaphor of the weighing scales, which almost inevitably comes up with the balancing semantics, can cause serious misunderstandings and thus warrants a word of caution. The main problem is that the two scales are imagined symmetrical-otherwise the metaphor would not make sense. Putting conflicting "goods" (or values, arguments etc.) on the scales thus implies testing the weight of both sides. This furthermore nourishes the expectation that the solution will somehow lie in the middle ground, of course depending on the weight of the arguments presented on both sides. Rather than placing the burden of justification systematically on one side only, as requested by the critical function of limitation clauses, balancing processes amount to sharing the burden between both sides, or so it may seem. However, this would lead to a reading of article 18(3) ICCPR, such that the proponents of FoRB and the proponents of, say, public safety and public order, are in a similar situation in that they both have to present persuasive arguments, whose weight will subsequently be checked. Instead of starting on the assumption that FoRB is a high-ranking legal entitlement, against which limitations need to be plausibly justified, the status and scope of FoRB may thus become shaky in the face of conflicting normative considerations and interests. At the end of the day, FoRB could factually lose its status as an inalienable right and be

(Oxford: Oxford University Press, 2012), p. 265: 'The State ... should be obligated to prove that the threats to the public order, public health, and the like are real and measurable rather than merely speculative or ideological, as well as that the proposed restrictions would actually reduce the danger.' 
reduced into an unreliable "grant", depending on volatile political circumstances. Guglielmo Verdirame therefore warns that an unqualified use of the balancing metaphor invites trade-offs, which in the long run could erode the special status of human rights: 'A right that is balanceable and negotiable cannot be fundamental. ${ }^{17}$

There is another danger connected with the image of the weighing scales. It can suggest a zero-sum-logic between the (seemingly or factually) conflicting interests. The more one scales sinks down, the more the other scale will move up, and vice versa. Whatever one party gains, the other will lose. Since the sum total of gains and losses does not change, this type of conflict has been termed zero-sum-conflict. However, in many normative conflicts involving human rights the ascribed zero-sum-logic may prove empirically wrong. An example is the frequently assumed antagonism between freedom and security in the context of anti-terrorism laws. While concrete conflicts between human rights issues, including FoRB, on the one hand and security concerns on the other can doubtlessly arise, one should be careful not to conceptualize such conflicts too quickly as an abstract zero-sum-antagonism. For instance, ample experience demonstrates that restrictive measures, which cut down on human rights and fundamental freedoms, do not always improve public safety. Instead of focusing strictly on the real threats, such measures sometimes arbitrarily target broader communities, exacerbate existing or emerging fault lines and create an atmosphere of mistrust, often at the expense of minorities, critics and dissidents. Obviously, none of this would serve purposes of trust-building and peace. By contrast, trying to preserve the substance of human rights also in conflict situations by sticking to a narrow application of limitation clauses can prove beneficial for public safety. Limitation clauses oblige the government to present compelling arguments that the adopted measures remain in line with all the prescribed criteria. Thus, the population at large and in particular those who are mainly affected by such restrictions, should be able to understand why the adopted measures are inevitable and what the government does to avoid discriminatory effects, for instance against certain religious minorities. While this places a heavy burden on the authorities, it may actually serve the overarching purpose of building institutional confidence in society. ${ }^{18}$ This is just one example illustrating that one should generally be cautious to describe real

17 Guglielmo Verdirame, 'Rescuing Human Rights from Proportionality', in S. Rowan Cruft et al. (eds.), Philosophical Foundations of Human Rights (Oxford: Oxford University Press, 2015), p. 354.

18 See Heiner Bielefeldt and Michael Wiener, Religious Freedom under Scrutiny (Philadelphia: University of Pennsylvania Press, 2020), pp. 184-186. 
or assumed conflicts too quickly in the zero-sum-mode. The balancing language, with its implied metaphor of the weighing scales harbours the risk of doing exactly that.

Of course, it would be foolish to try generally to eradicate the balancing semantics in the interpretation of limitation clauses. The popularity of that language points to a widely felt intuitive plausibility. Moreover, balancing often represents the praiseworthy aspiration to take different perspectives and interests into consideration. At the same time, it is advisable to be aware of possible misunderstandings, which can easily emerge from the underlying metaphor of the weighing scales. In order to preserve the critical force of limitation clauses, one should insist on strict justification requirements, which generally fall on those arguing for limitations; it is up to them to carry the burden of argumentation. At a closer look, the logic of justification requirements thus differs essentially from putting competing arguments on the weighing scales, and it is important to be clear about that conceptual difference.

\section{Conflicts in the Intersection of Different Human Rights}

The list of purposes that can be invoked for limiting FoRB entails 'the fundamental rights and freedoms of others'. Many examples come to mind where the use of FoRB collides, or seems to collide, with the rights of others: Parents have referred to the religious socialization of their children, which is part of their FoRB, ${ }^{19}$ in order to receive exemptions from sports, swimming or biology classes, even though that would infringe on their children's right to education. The religion-based refusals to undergo certain forms of medical treatment can harbour health risks not only for the concerned persons themselves, but also for others, which thus would affect their right to health. Tensions between FoRB and freedom of expression have come up, for instance, in the case of blasphemy discussions, even though the role of FoRB in such debates remains questionable; I will come back to this issue later. Many prominent cases concern conflicts between FoRB and gender-related rights. For instance, in the eyes of critics, the Islamic headscarf, which some women wish to wear as part of their FoRB, symbolizes the unequal status of men and women. Conservative Christian hotel owners refusing to host gay couples have tried to justify their position by referring to their own religious convictions. Registrars at local

19 See article 18(4) of the ICCPR as well as article 14 of the Convention of the Rights of the Child (CRC). The significance of the CRC for understanding parental rights in the area of FoRB generally does not receive sufficient attention. 
authorities not wishing to get professionally involved with same-sex marriage ceremonies have claimed conscientious objection on religious grounds. Obviously, this random list of examples is far from exhaustive. ${ }^{20}$

How does the above reflection on the burden of justification apply to configurations where human rights issues are on both sides of the equation? Obviously, things are more complicated in this type of conflict. Does this mean that we have to move back to square zero and resort to "balancing" procedures as the most plausible answer? At first glance, this seems to be the case. Unlike in situations of tension between FoRB and public safety or public order, where the burden of justification falls on the side of those proposing limitations, in cases of colliding human rights concerns, some "burden sharing" between both sides seems inevitable. Nonetheless, the principles elaborated above, fully apply_albeit in a more complex way. The task remains to preserve the substance of human rights - now of all the legitimate human rights concerns at issue in a particular case - to the maximum degree possible. This requirement rules out two popular assumptions, both of which regularly come up in respective discussions. The first problematic assumption is that one right should generally overrule the other. The second assumption would be that one has to settle the conflict by a compromise, more or less in the middle ground between the competing human rights concerns.

The idea that one right generally overrules the other right has found expression in the metaphor of a card game, where the stronger card simply "trumps" the other. Understanding rights in analogy to that metaphor means that, at the end of the day, only the trumping right will count. There is a grain of truth in that assumption. What is true is that decisions based on setting a concrete priority are sometimes just unavoidable. However, when it comes to normative conflicts involving human rights, the logic of "winner takes it all" cannot be the guiding principle. The defeated party, too, should be able to feel that their human rights-based concerns have at least been taken seriously, or this is the aspiration..$^{21} \mathrm{~A}$ conflict between different human rights concerns cannot legitimately be resolved by postulating an abstract hierarchy between these rights, with the result that one right would eventually be sacrificed in favour of the other. This would go against the idea that ultimately all human rights belong together, since they all are 'universal, indivisible and interdependent

$20 \quad$ See Peter Cumper, 'Freedom of Religion and Human Rights Laws-Awkward Bedfellows', in Burri S. van den Brink and Jenny Goldschmidt (eds.), Equality and Human Rights: Nothing but Trouble? (sIm Netherlands Institute of Human Rights, 2015), pp. 283-304.

21 See Maria J. Valero Estrellas, 'State Neutrality, Religion, and the Workplace in the Recent Case Law of the European Court of Human Rights', in W. Cole Durham, Jr. and Donlu Thayer (eds.), Religion and Equality. Law in Conflict (London: Routledge, 2015), pp. 35-55. 
and interrelated. ${ }^{22}$ The trumping-right approach obfuscates that important insight into the indivisibility of all human rights.

The second assumption is no less problematic. It builds on the general experience that conflict settlement requires willingness on all sides to find some comprise - or as one may prefer to call it: to strike a "balance". The image of the weighing scales seems to offer itself as a guiding idea. Again, there is an element of truth in this assumption. In the area of human rights, too, compromises are often inevitable, in particular in situations of competing rightsbased claims. If in a conflict each of the parties insist on the maximum for themselves, a solution may become just impossible. At the same time, it remains important not to give in too quickly, since this count amount to selling out the substance of human rights, which themselves are inalienable rights, after all. Now, the term "compromise" appears to suggest that the solution will somehow lie in the middle ground between the competing rights. While the trumping-right approach implies that the winner gets a hundred per cent and the loser will receive zero, the idea of a compromise somehow points into the direction of fifty-fifty. What both positions have in common, however, is that they assume the structure of a zero-sum-conflict. This is the main problem.

Taking human rights seriously implies ongoing efforts to avoid the zerosum-logic - as far as possible. ${ }^{23}$ The ideal solution when it comes to coordinating different human rights concerns would be to preserve hundred per cent of each the legitimate claims at issue. This is less of a utopia than it may sound. A careful analysis can at times yield the result that a supposed conflict does not even exist or is much less absolute than was presumed at first glance. Take the example of headscarf bans typically issued on the questionable assumption that the hijab per se signifies a subordinated status of women; this has often become an argument for cutting down on FoRB. I am not saying that conflicts in this area do not exist. It all depends on the specific context, but it can well be that in a particular situation full respect for FoRB proves quite compatible with promoting full gender equality. What prima facie looks like a conflict, best to be solved by a compromise, may sometimes turn out to be a case for creating positive synergies. Another example concerns alleged tensions between FoRB and freedom of expression, for instance, around blasphemy charges. Scholars, commentators and even judges have often assumed that FoRB protects believers against disparaging cartoons or speech acts deemed "blasphemous".

22 UN General Assembly, Vienna Declaration and Programme of Action (A/CONF.157/24), Part I, chap. III, sect. I, paragraph 5 .

23 I do not deny the zero-sum-logic may adequately describe an existing conflict situation. 
However, there are good arguments that FoRB does not have this function. ${ }^{24}$ As a human right, it protects human beings in their freedom relating to issues of religion or belief, while not including protection of religions in themselves, let alone of their honour or reputation. Thus, at a closer look, some of the assumed conflicts between FoRB and freedom of expression actually turn out not even to exist, depending on the specific context. Instead of calling for a compromise, presumably somewhere in the middle ground of both claims, it may be possible to preserve both of the two rights full scale. The zero-sumlogic would rule out that possibility; this is the problem.

Even in situations where a conflict obviously does exist, the task remains to do justice, to the maximum degree possible, to each of the rights concerned. If the ideal solution of preserving a hundred per cent of each of the rights is no realistic option, one should still try to remain as closely as possible to that ideal. Any deviation from the full substance of each of the rights requires a specific justification, as to which exact purpose this is supposed to serve, why it is actually necessary to impose a limitation in order to accomplish the said purpose, why that limitation is the mildest of all available options and what the government does to avoid discriminatory side effects. Instead of replacing justification requirements by a vague "balancing" exercise, the need to justify any proposed limitation remains fully applicable-albeit in a more complex manner. Konrad Hesse, an influential German lawyer and judge, once termed the task at hand "praktische Konkordanz" (literally: "practical concordance"). ${ }^{25}$ What we need, according to Hesse, is a careful, context-sensitive coordination of all the rights involved in a particular situation, with the intention to preserve the maximum content of all of them.

\section{5}

Absolute Limits of Justifiability: the Forum Internum

As mentioned already, human rights institutionalize respect for human dignity. Taking the effort to justify limitations to human rights, particularly in view of those bearing the practical consequences, is likewise a manifestation of respect. Such justification, if adequately practised, reconfirms the status of human beings as responsible agents, who are entitled to know what happens and to understand the reasons for certain inevitable infringements of their rights. This matches every-day experience. Take the example of security checks

24 See Bielefeldt, Ghanea, and Wiener, supra note 9, pp. 481-506.

25 See Konrad Hesse, Grundzüge des Verfassungsrechts der Bundesrepublik Deutschland (Heidelberg: C.F. Müller, 2oth edition reprint, 1999), paragraph 70. 
at airports which, if comparatively mildly, interfere with a person's rights to privacy and liberty. While no one likes to undergo such checks, people usually do not feel humiliated thereby - provided they can understand the purpose of such security measures and can reasonably believe that the staff refrain from discriminatory treatment and avoid unnecessary burdens. This trivial example illustrates the way justification requirements operate in general. By demanding plausible explanations and holding governments to account for what they do, they confirm the position of right holders even in situations where limitations may eventually prove necessary.

In a study titled The Right to Justification, Rainer Forst elaborates the significance of justification requirements for the understanding of the human rights approach in general. ${ }^{26}$ When seen from that perspective, limitation clauses are a central element of human rights, because they spell out in detail the insistence on justification. Accordingly, it would be inappropriate to treat them as mere formalities or technicalities. No less than the substantial guarantees of rights, these and similar procedures, too, epitomize the due respect for everyone's dignity. Hence, limitation clauses are not an unpleasant or even awkward theme in human rights theory. When adequately conceptualized and practised as "Schranken-Schranken" - i.e. limiting the scope of permissible limitationsthey have a positive protective role to play.

As manifestations of respect, justification procedures must have their inherent limitations. Not everything can receive a justification, as soon as mighty interests enter the picture. The ultimate limits of justifiability come out in certain absolute prohibitions, for instance, the ban on torture or the prohibition of slavery. ${ }^{27}$ These prohibitions represent the "red lines", which can never be legitimately crossed, because torture and slavery completely nullify the respect that is due to all human beings in their potential of responsible agency. The right to FoRB, too, entails an aspect of absolute prohibition. Article 18(2) of the ICCPR demands categorically that 'No one shall be subject to coercion which would impair his freedom to have or adopt a religion or belief of his choice.' Whereas article 18(3) deals with external manifestations of FoRB, article 18(2) focuses on the forum internum, whose protection is even stronger; indeed, it is absolute in the sense of being immune from any legitimate interferences whatsoever. Infringing coercively the inner nucleus of a person's convictionformation means no less than denying the affected individual his or her status as a moral agent. However, this would violate the underlying logic of

26 See Rainer Forst, The Right to Justification (New York: Columbia University Press, 2014).

27 See articles 7 and 8 of the ICCPR. 
justification. ${ }^{28}$ General Comment no. 22 confirms this absolute prohibition when pointing out that article 18 'does not permit any limitations whatsoever on the freedom of thought and conscience or on the freedom to have or adopt a religion or belief of one's choice. These freedoms are protected unconditionally ...'29

Some critics of FoRB have objected that article 18(2) of the ICCPR privileges the inner dimension of FoRB as compared to external manifestations, thus allegedly reflecting a "Protestant" bias in the understanding of religiosity. ${ }^{30}$ As long as one deals with article 18 in isolation, this impression may actually emerge. However, one should see article 18(2) in conjunction with other absolute prohibitions in human rights law, like the absolute bans on torture and slavery. Together with those equally unconditional prohibitions, the categorical rejection of coercive interferences into the nucleus of a person's faithformation reminds us of the important role of justification procedures for the human rights approach in general. When seen in that broader perspective, the charge of a "Protestant" bias loses much of its persuasiveness. ${ }^{31}$ Moreover, while the two dimensions of forum internum and forum externum are distinguishable at the conceptual level, they do belong together at the phenomenological level. Serious convictions built in the forum internum always imply an urge on the concerned person to live accordingly and thus to manifest those convictions in the external world. At the same time, external manifestations of religion or belief would lack any strength unless they are rooted in an inner conviction. Article 18 of the ICCPR underlines such a holistic understanding of

28 Manfred Nowak and Tanja Vorspernik trivialize the forum internum of freedom of religion or belief by confusing it with the "private" application of this right. See Manfred Nowak and Tanja Vorspernik, 'Permissible Restrictions on Freedom of Religion or Belief', in Tore Lindholm et al. (eds.) Facilitating Freedom of Religion or Belief: A Deskbook (Leiden: Martinus Nijhoff Publishers, 2004), p. 148. When the authors (on p. 149) wonder how to "balance the right to teach religious views and to convince others with the "absolute" right of others not to suffer violation of their forum internum' (emphasis in the original), they ignore the important fact the right to convert others only covers non-coercive forms of communicative persuasion. Leaving aside the relativistic language of "balancing", there is not even a conflict that would possibly permit invoking the limitation clause.

29 General Comment no. 22, supra note 4, paragraph 3.

30 See e.g. Elizabeth Shakman Hurd, 'Believing in Religious Freedom', in Winnifred Fallers Sullivan et al. (eds.), Politics of Religious Freedom (Chicago: University of Chicago Press, 2015), pp. 45-56.

31 For a detailed discussion of the allegedly one-sidedly protestant features of FoRB, see Bielefeldt and Wiener, supra note 18, pp. $3^{1-36 .}$ 
FoRB in its first paragraph. Before distinguishing between internal and external dimensions, the article defines the full spectrum of FoRB, which comprises internal and external dimensions equally:

Everyone shall have the right to freedom of thought, conscience and religion. This right shall include freedom to have or to adopt a religion or belief of his choice, and freedom, either individually or in community with others and in public or private, to manifest his religion or belief in worship, observance, practice and teaching.

\section{$6 \quad$ Concluding Remarks}

Limitation clauses are an important feature of human rights provisions. Unfortunately, however, they are exposed to numerous misunderstandings. Governments, in particular authoritarian governments, frequently twist these clauses into general permissions to impose limitations to human rights. In extreme cases, human rights provisions thus end up as empty promises, since governments claim broad leeway in defining and redefining their scope and limitations, as they see fit. It is all the more important to understand the role of limitation clauses as limiting the scope of permissible limitations, thus protecting the substance of human rights even in conflict situations. Taking this critical function seriously implies empirical diligence and normative precision. Any limitation where deemed necessary requires a compelling justification, in conformity with the criteria set out for this purpose. The ubiquitous "balancing" metaphor does not adequately describe the task at issue, thus nourishing wrong conceptualizations. Moreover, justification is not an empty, merely "formalistic" procedure, but ultimately epitomizes respect for the dignity of human beings as responsible agents. That is why not everything is justifiable. For good reasons, human rights law-despite a certain degree of pragmatic elasticity-entails absolute prohibitions, like the prohibitions of torture, slavery or brainwashing.

In this article, I have focused on article 18 of the ICCPR. However, the general principles demonstrated with reference to this example are more broadly applicable. For instance, the FoRB provision in article 9 of the European Convention on Human Rights (ECHR) follows the same logic as article 18 of the ICCPR. A strict interpretation of the limitation clause in article 9(2) of the ECHR, can give rise to many questions concerning the jurisdiction of the European Court of Human Rights, which often does not show the required 
rigour in the application of the limitation clause. ${ }^{32}$ Other rights to freedom, such as freedom of expression, freedom of peaceful assembly, freedom of association, etc., likewise carry limitation clauses analogously to the one interpreted here. While it is advisable to stick to the precise wording used in each of the respected articles, one should always bear in mind the protective function of limitation clauses. The Siracusa Principles adopted by the UN, deal with limitation clauses within the ICCPR broadly. One of their main messages is that '[a]ll limitation clauses shall be interpreted strictly and in favour of the rights at issue. 33

32 See the critical comments by Thiago Alves Pinto, 'An Empirical Investigation of the Use of Limitations to Freedom of Religion or Belief at the European Court of Human Rights', included in this same issue.

33 UN Economic and Social Council, Siracusa Principles on the Limitation and Derogation of Provisions in the International Covenant on Civil and Political Rights (E/CN.4/1984/4, Annex), General Principle no. 3. 